\title{
Amer F. Samdani, Peter O. Newton, Paul D. Sponseller, Harry L. Shufflebarger, Randal R. Betz: Neuromuscular spine deformity: A Harms Study Group treatment guide
}

\section{Thieme Verlag New York, Stuttgart, Delhi, Rio de Janeiro, 2018, 206 pp, 264 figs., Hardcover, EUR(D) 159,99 EUR(A) 164,40 CHF 184,00, ISBN: 978-1-62623-260-0}

\author{
Pierre H. Kehr ${ }^{1}$
}

Received: 10 July 2019 / Accepted: 20 July 2019 / Published online: 25 July 2019

c) Springer-Verlag France SAS, part of Springer Nature 2019

Scoliosis of neurological origin is an important therapeutic problem. Publishers have engaged a large number of North American specialists to study all diagnostic aspects and considerations of surgical or conservative treatment.

After important general considerations, such as surgical indications in this severe scoliosis, problems of anesthesia, the prediction of complications, and the different diagnoses of neurological scoliosis are studied. These include scoliosis in cerebral palsy, myelomeningocele, and Duchenne dystrophy. All cases are abundantly illustrated by pre- and postoperative radiographs.

Then follows an important part dedicated to the surgical techniques, the use of the halo for preoperative traction, osteotomies and vertebral resections, the posterior and anterior surroundings, the treatment of the early and late infections, the reinterventions, and the appreciation of the quality life of the operated.

This book is essential not only to spine surgeons, but also to pediatricians and neurologists so that they know how to guide their patients with these serious deformities.

\section{Compliance with ethical standards}

Conflict of interest The author declares that they have no competing interests.

Publisher's Note Springer Nature remains neutral with regard to jurisdictional claims in published maps and institutional affiliations.
Pierre H. Kehr

pierre.kehr@gmail.com

1 Strasbourg, France 